\title{
Removal of Cr(VI) Ions Using a Binary Grafting of N-Vinylcaprolactam and N,N -Dimethylacrylamide onto Crosslinked Chitosan, Synthesized by Gamma Radiation
}

\author{
Zaira Patiño, Alejandra Ortega, Guillermina Burillo* \\ Instituto de Ciencias Nucleares, Universidad Nacional Autónoma de México, Ciudad Universitaria, Av. \\ Universidad \#3000, CP 04510, Ciudad de México, México.
}

*Corresponding author: Guillermina Burillo, e-mail: burillo@nucleares.unam.mx, Tel: +525556233383

Received June 19 ${ }^{\text {th }}, 2019 ;$ Accepted August 24 $4^{\text {th }}, 2019$.

DOI: http://dx.doi.org/10.29356/jmcs.v63i4.980

\begin{abstract}
Chitosan is characterized by its good affinity of metal ions due to high amount of amino groups. However, crosslinking of chitosan results in a dramatic decrease of retention properties due to reaction of amino groups during process. N,N-dimethylacrylamide (DMAAm) increases the hidrophilicity of the system and improve the apparent mechanic properties; while N-vinylcaprolactam (NVCL), a temperature stimuli sensitive monomer with a LCST of about $32{ }^{\circ} \mathrm{C}$, makes possible for reuse the material. Adsorption of $\mathrm{Cr}(\mathrm{VI})$ onto crosslinked chitosan (net-CS) and NVCL/DMAAm binary grafted system onto net-CS, synthesized by gamma radiation of ${ }^{60} \mathrm{Co}$, has been investigated. The experimental results obtained from equilibrium adsorption studies are fitted in Langmuir and Freundlich isotherms. The Langmuir model agreed better, indicating that adsorption process is carried out homogeneously onto surface. The maximum adsorption capacity was 24.63 and $55.2 \mathrm{mg}$ $\mathrm{g}^{-1}$ for net-CS $(1 \%)$ and net-CS $(3 \%)$, respectively. The maximum retention was obtained from the binary grafted system (21\%) onto net-CS (3\%) with $142.86 \mathrm{mg} \mathrm{g}^{-1}$.
\end{abstract}

Keywords: Chitosan networks; $\mathrm{Cr}(\mathrm{VI})$ retention; adsorption isotherms; radiation grafting; Nvinylcaprolactactam.

Resumen. El quitosano se caracteriza por tener una buena afinidad con diferentes iones metálicos debido a la alta cantidad de grupos amino que contiene. Sin embargo, la reticulación del quitosano da como resultado una disminución dramática de las propiedades de retención debido a la reacción de los grupos amino durante el proceso. La N,N-dimetilacrilamida (DMAAm) aumenta la hidrofilicidad del sistema y mejora las propiedades mecánicas aparentes, mientras que la $\mathrm{N}$-vinilcaprolactama (NVCL), un monómero termosensible con una LCST de aproximadamente $32{ }^{\circ} \mathrm{C}$, hace posible la reutilización del material. La adsorción de $\mathrm{Cr}(\mathrm{VI})$ en quitosano entrecruzado (net-CS) y en un sistema binario injertado de NVCL/DMAAm sobre net-CS, fue estudiado. Los resultados obtenidos de los estudios de adsorción de equilibrio se ajustaron a las isotermas de Langmuir y Freundlich. El modelo de Langmuir coincidió mejor, lo que indica que el proceso de adsorción se lleva a cabo de manera homogénea sobre la superficie. La capacidad máxima de adsorción fue de 24.63 y $55.2 \mathrm{mg} \mathrm{g}^{-1}$ para net-CS (1\%) y net-CS (3\%), respectivamente. La máxima retención se obtuvo para el sistema binario injertado (21\%) sobre net-CS (3\%) con $142.86 \mathrm{mg} \mathrm{g}^{-1}$.

Palabras clave: geles de quitosano; retención de $\mathrm{Cr}(\mathrm{VI})$; isotermas de adsorción; injerto por radiación; Nvinilcaprolactama. 


\section{Introduction}

As a result of increasing industrial activity, contamination of water resources with toxic heavy metals is becoming a serious problem. Chromium is commonly employed in leather tanning, electroplating, metal finish, paints and textile industries. Toxic metals as chromium should be removed before coming in contact with the environment. Chromium exists in various oxidation states but in aqueous solutions the most stable are the $\mathrm{Cr}(\mathrm{VI})$ and $\mathrm{Cr}(\mathrm{III})$ states. $\mathrm{Cr}(\mathrm{VI})$ is significantly more toxic than trivalent, even at low concentrations with a potential carcinogenic and mutagenic effect to living organism; the limit value of chromium in drinking water is $0.05 \mathrm{mg} \mathrm{L}^{-1}$. Several methods are used to remove $\mathrm{Cr}(\mathrm{VI})$ from aqueous solutions, such as electrolysis, reverse osmosis, ion exchange, solvent extraction and absorption among others [1-5]. The absorption method is considered the most cost effective and efficient method of removing $\mathrm{Cr}(\mathrm{VI})$ from aqueous solutions.

Chitosan (CS) is a natural polysaccharide, obtained from deacetylation of chitin, which is the second most abundant natural biopolymer. CS is commonly used to remove metal ions and dyes from wastewater because of amino and hydroxyl functional groups [6]. Moreover, it is possible to modify the inherent properties of CS to improve its performance introducing different functional groups into structure. Chemical modification can be made by several methods, but radiation grafting offers advantages such as the reaction could be carried out without any additives, at any temperature, and different monomers can be grafted onto substrate [7-9].

The objective of this work was to study the possibility of improving the $\mathrm{Cr}(\mathrm{VI})$ adsorption capacity of net-CS, modifying it with a binary grafting of $\mathrm{N}$-vinylcaprolactam and $\mathrm{N}, \mathrm{N}$-dimethylacrylamide by gamma radiation. NVCL is a nonionic, nontoxic, thermal sensitive monomer with a lower critical solution temperature (LCST) of $\sim 32^{\circ} \mathrm{C}$, while DMAAm is a hydrophilic monomer, able to improve the mechanical properties of materials. Both monomers contain carboxylic and amide groups, suitable for the retention of heavy ions.

\section{Experimental}

\section{Materials}

$\mathrm{N}$-vinylcaprolactam and N,N-dimethylacrylamide from Sigma-Aldrich, Mexico was vacuum distilled before use; chitosan of low molecular weight $\left(1 \times 10^{6}\right), \mathrm{K}_{2} \mathrm{CrO}_{4}$ and formaldehyde from Sigma-Aldrich Mexico, and acetic acid from T. Baker were used as received. Distilled water was used in all experiments.

\section{Crosslinking of CS}

Deacetylation of $70.8 \%$ was determined by titration methods [10]. Two different solutions of CS were prepared $(1 \%$ and $3 \% \mathrm{w} / \mathrm{v})$ in acetic acid solution $10 \%(\mathrm{v} / \mathrm{v})$, and subsequently crosslinked. Briefly, $10 \mathrm{~mL}$ of formaldehyde ( $37 \% \mathrm{wt}$ in $\mathrm{H}_{2} \mathrm{O}$ ) was added into $100 \mathrm{~mL}$ of CS solution; it was stirred for $2 \mathrm{~h}$ and then vacuum dried for $96 \mathrm{~h}$. The net-CS at different concentrations ( $n \mathrm{CS} 1$ and $n \mathrm{CS} 3$ ) were washed with acetic acid solution $(1 \% \mathrm{v} / \mathrm{v})$ to eliminate un-crosslinked $\mathrm{CS}$, and later with water until reached neutral $\mathrm{pH}$. The experiments were carried out by triplicate. The crosslinking reaction yield was calculated with the equation (1).

$$
\operatorname{Gel}(\%)=\frac{W_{f}}{W_{0}} x 100
$$

where, $\mathrm{W}_{\mathrm{f}}$ and $\mathrm{W}_{\mathrm{o}}$ are the weight of insoluble crosslinked CS and the initial CS, respectively.

\section{Binary grafting of NVCL/DMAAm onto crosslinked CS}

The $n$ CS was grafted by direct irradiation method, in one step, according to Perez-Calixto et al [11]; $0.2 \mathrm{~g}$ of $n$ CS was placed in glass ampoules with $7 \mathrm{~mL}$ of NVCL/DMAAm $(15 / 5 \% \mathrm{v} / \mathrm{v})$ methanol solution. The system was swelled during $24 \mathrm{~h}$, the excess of solution was separated, and the ampoules were bubbled with argon for $20 \mathrm{~min}$ to eliminate oxygen and sealed. The samples were irradiated at $10 \mathrm{kGy}$ with a dose rate of 9.5 
$\mathrm{kGy} \mathrm{h}^{-1}$. The binary grafting system (BGnCS) was washed with acetic acid solution $(1 \% \mathrm{v} / \mathrm{v})$ and water to remove residual monomer and homopolymer. The samples were filtered and vacuum dried, and the grafting percentage calculated with equation (2).

$$
\operatorname{Graft}(\%)=\frac{W_{g}-W_{0}}{W_{0}} \times 100
$$

where, $\mathrm{W}_{\mathrm{g}}$ and $\mathrm{W}_{\mathrm{o}}$ are the weights of the binary graft copolymer and initial crosslinked CS, respectively.

\section{Batch Cr(VI) retention experiments}

To determine the kinetic of $\mathrm{Cr}(\mathrm{VI})$ ions removal, batch type experiments were carried out by triplicate at $25^{\circ} \mathrm{C} .100 \mathrm{mg}$ of $n \mathrm{CS}$ or $\mathrm{BG} n \mathrm{CS}$ were shaken in closed vials with $10 \mathrm{~mL}$ of $\mathrm{Cr}(\mathrm{VI})$ aqueous solution, with a $\mathrm{pH}$ value of 5.5. The change in chromium concentration was monitored by ultraviolet spectroscopy at $275 \mathrm{~nm}$ (UV-Vis spectrometer SPECORD200 Plus, Analytik Jena, Germany). The absorption capacity of the systems was quantified from calibration curve using the absorbance changes in function of concentration. The used linear equation is $\mathrm{Abs}=0.0237[\mathrm{Cr}(\mathrm{VI})]+0.0251\left(\mathrm{R}^{2}=0.9984\right)$, which is valid between 2 and $100 \mathrm{mg} \mathrm{Cr}(\mathrm{VI})$ $\mathrm{L}^{-1}$. The precision range of the spectrophotometer was \pm 0.008 absorbance.

\section{Adsorption isotherms of $\mathrm{Cr}(\mathrm{VI})$}

The equilibrium sorption of $\mathrm{CrO}_{4}{ }^{2-}$ was carried out onto $n \mathrm{CS}$ and $\mathrm{BG} n \mathrm{CS}$ as mentioned earlier. Solutions with different concentrations of $\mathrm{K}_{2} \mathrm{CrO}_{4}$ were prepared by dilutions of a stock solution of $1.0 \times 10^{-3}$ mol L-1 in distilled water. Samples were placed into solutions and the concentration was analyzed by UV spectroscopy. The experiments were performed at $25^{\circ} \mathrm{C}$ by triplicate. The data was fitted into Freundlich and Langmuir isotherms.

\section{Results and Discussion}

The crosslinking yield of nCS1 was $56.8 \pm 0.52 \%$ while for nCS3 was $90.7 \pm 1.6 \%$. In order to choose an appropriate solvent to graft the monomers, the swelling behavior was studied in methanol and dimethylformamide (Fig. 1). Water was not considered due to high swelling of net-CS in this solvent ( $400 \%)$, that causes a diminishing in mechanical properties. nCS3 reached the equilibrium swelling at $60 \mathrm{~min}$, and methanol was a better solvent with a $\sim 5 \%$ swelling, compared to the $\sim 30 \%$ swelling in DMF. A similar behavior was shown in nCS1 (43\% and $28 \%$ in methanol and DMF, respectively). Therefore, net-CS swelling degree in methanol is enough for carrying out the grafting reaction. 


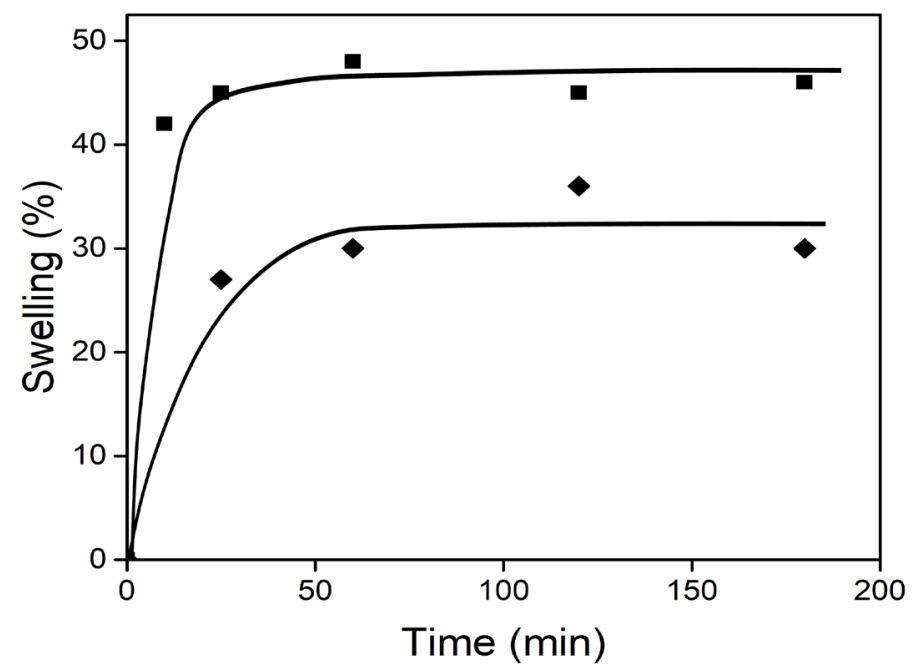

Fig. 1. Swelling behavior of $\mathrm{nCS} 3$ as a function of time: $\bullet \mathrm{DMF}$; $\mathrm{MeOH}$

Fig. 2 shows the binary graft of the monomers onto net-CS as a function of dose. In the first case, the yield of grafting onto nCS3 increased with the dose and a maximum grafting percentage of $35 \%$ was obtained at 15 kGy (Fig.2(a)). In the case of nCS1, the binary graft of the monomers decreased with the dose, but higher grafting percentages were obtained (Fig.2(b)). This behavior is due to an easier diffusion of monomers into nCS1 than nCS3, causing a higher swelling and a big grafting yield. By other side, it is well known that chitosan undergoes degradation with gamma radiation [12], but the nCS1 was degraded faster than nCS3.
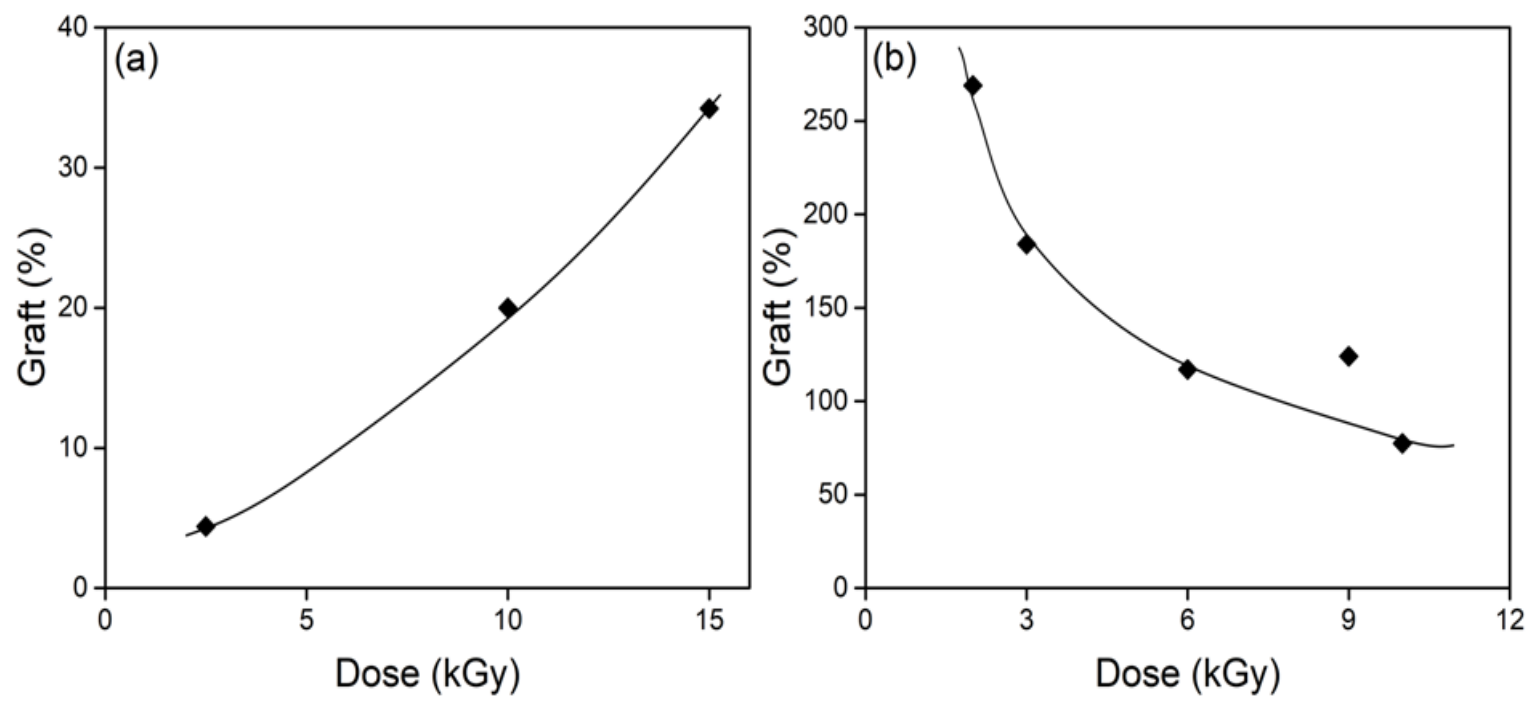

Fig. 2. Binary graft onto net-CS at different CS initial concentration, as a function of dose; (a) nCS3 (b) nCS1. [NVCL/DMAAm]: 15/5\% v/v, in methanol. 


\section{Determination of contact time for the maximum $\mathrm{Cr}(\mathrm{VI})$ retention}

In spite to determinate the optimal time contact for $\mathrm{Cr}(\mathrm{VI})$ retention study, three grafted samples with different grafting percentages were chosen: BGnCS1 (184\%), BGnCS1 (200\%) and BGnCS1 (270\%). The results can be observed in Fig. 3, it is clear that retention increased rapidly, and then leveled off at the maximum retention of equilibrium time. The retention onto nCS1 was about $17 \mathrm{mg}^{\circ} \mathrm{Cr}(\mathrm{VI}) \mathrm{g}^{-1}$ of sample at $800 \mathrm{~h}$. In case of binary grafting, the retention time was lower and depended of grafting percentage. Therefore, the $\mathrm{Cr}(\mathrm{VI})$ retention reached about $30 \mathrm{mg} \mathrm{g}^{-1}$ at only $3 \mathrm{~h}(180 \mathrm{~min})$ in BGnCS1 $(270 \%)$, while BGnCS1 (184\%) retained only $10 \mathrm{mg} \mathrm{g}^{-1}$. This decrease in the equilibrium retention time was due to the grafted chains were swelled too and they put more pressure into network, accelerating the swelling process.
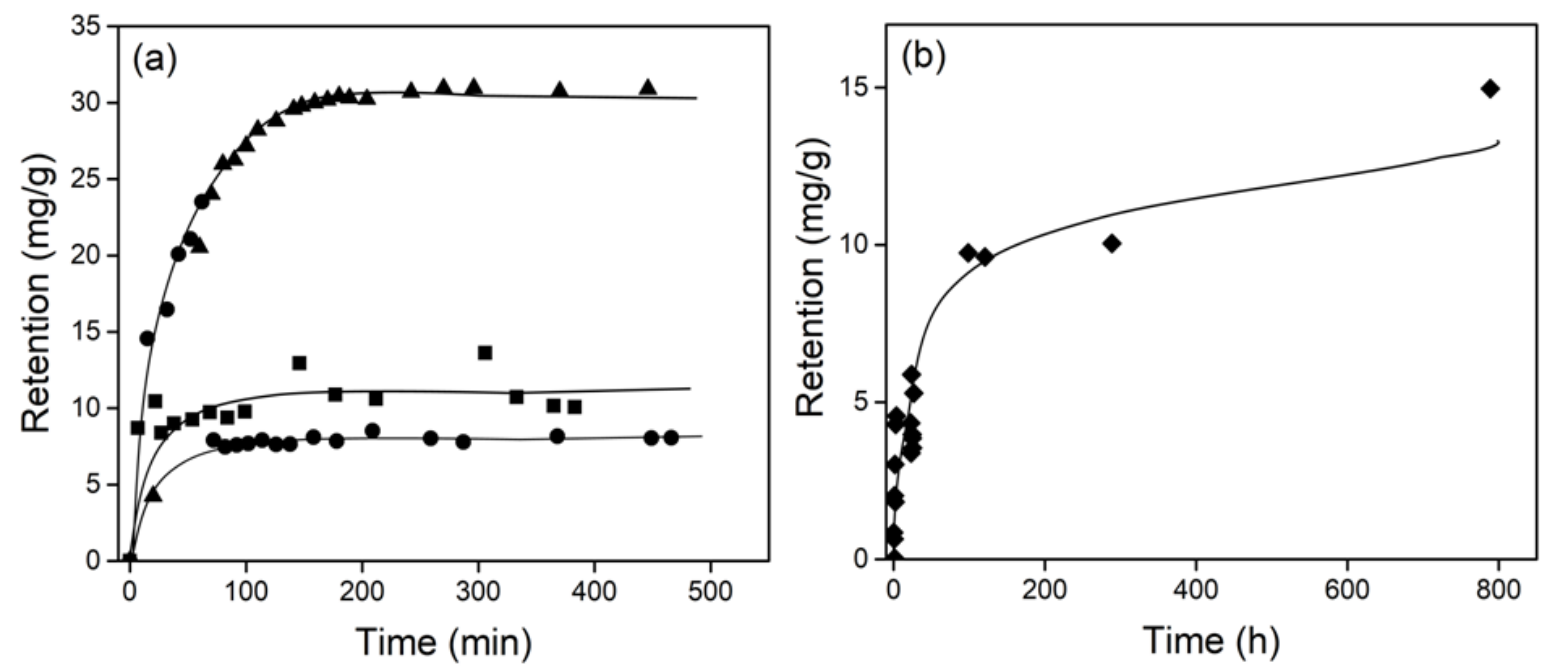

Fig. 3. $\mathrm{Cr}(\mathrm{VI})$ retention as a function of time. (a) BGnCS1 at different percentages: $\mathbf{\bullet} 184 \%, \bullet 200 \%, \boldsymbol{\Delta} 270 \%$; (b) $\mathrm{nCS} 1 .\left[\mathrm{K}_{2} \mathrm{CrO}_{4}\right]: 5 \times 10^{-4} \mathrm{M}$.

\section{Retention of chromium as a function of the initial concentration}

The effect of initial concentration of $\mathrm{Cr}(\mathrm{VI})$ on the maximum percentage of retention in samples with different binary grafting percentages can be observed in Table 1 .

Table 1. Equilibrium $\mathrm{Cr}(\mathrm{VI})$ retention $\mathrm{Q}_{\mathrm{e}}$ and retention percentage at different chromate concentrations and binary graft percentages.

\begin{tabular}{|l|c|c|c|c|c|c|c|c|}
\hline \multirow{2}{*}{$\begin{array}{c}\mathrm{K}_{\mathbf{2}} \mathbf{C r O}_{\mathbf{4}} \\
{[\mathbf{M}]}\end{array}$} & \multicolumn{4}{|c|}{$\mathbf{Q}_{\mathbf{e}}\left(\mathbf{m g ~ g}^{-\mathbf{1}}\right)$} & \multicolumn{4}{c|}{ Retention (\%) } \\
\cline { 2 - 9 } & $\mathbf{n C S 1}$ & $\begin{array}{c}\text { BGnCS1 } \\
\mathbf{1 8 4 \%} \text { graft }\end{array}$ & $\mathbf{n C S 3}$ & $\begin{array}{c}\text { BGnCS3 } \\
\mathbf{2 1 \%} \text { graft }\end{array}$ & $\mathbf{n C S 1}$ & $\begin{array}{c}\text { BGnCS1 } \\
\mathbf{1 8 4 \%} \text { graft }\end{array}$ & $\mathbf{n C S 3}$ & $\begin{array}{c}\text { BGnCS3 } \\
\mathbf{2 1 \%} \text { graft }\end{array}$ \\
\hline $1 \times 10^{-4}$ & 9.18 & --- & 9.19 & 8.58 & 95.09 & --- & 95.21 & 92.04 \\
\hline $2 \times 10^{-4}$ & 15.09 & 16.78 & 16.49 & 17.67 & 78.17 & 89.93 & 97.08 & 95.23 \\
\hline $3.5 \times 10^{-4}$ & 24.33 & 28.40 & 32.08 & 31.74 & 75.52 & 85.9 & 98.28 & 97.81 \\
\hline $5 \times 10^{-4}$ & 23.3 & 14.85 & 35.52 & 45.94 & 48.10 & 31.46 & 95.92 & 97.48 \\
\hline
\end{tabular}

Maximum $\mathrm{Cr}(\mathrm{VI})$ retention $\left(\mathrm{Q}_{\mathrm{e}}\right)$ in net-CS and BGnCS increased with $\mathrm{Cr}(\mathrm{VI})$ solution concentration; all samples achieved to retain chromium ions but with different efficiencies (Table 1). Samples based on nCS3 had the best performance, achieving above $95 \%$ efficiency in the range of studied concentrations. Something important is the retention was better at lower grafting percentages such as BGnCS3 (21\%) sample. This was attributed to the additional binding affinity via incorporation of NVCL and the DMAAm in the hydrogel 
network structure. However, the retention capacity decreased when the graft percentage increased because the chains were longer and tangled, which did not allow the functional groups to be available to interact with $\mathrm{Cr}(\mathrm{VI})$ ions.

The capacity of the adsorbent can be described by equilibrium sorption isotherms. The sorption isotherms were investigated using two equilibrium models: Freundlich and Langmuir, which give information about the sorption process.

The Freundlich isotherm can be applied to non-ideal adsorption on heterogeneous surfaces as well as multilayer adsorption, and is expressed by the following equation:

$$
\log Q_{e}=\frac{1}{n} \log C_{e}+\log K_{F}
$$

where, Qe is the amount of adsorption of $\mathrm{Cr}(\mathrm{VI})$ at equilibrium $\left(\mathrm{mg} \mathrm{g}^{-1}\right)$, Ce is the equilibrium concentration $\left(\mathrm{mg} \mathrm{L}^{-1}\right), \mathrm{K}_{\mathrm{F}}$ and $1 / \mathrm{n}$ are the Freundlich constants corresponding to the adsorption capacity and empirical parameter of the intensity of adsorption, respectively. At high $\mathrm{K}_{\mathrm{F}}$ and $1 / \mathrm{n}$ values, the maximum retention capacity is higher and more favorable is the adsorption. If value of $1 / \mathrm{n}$ is below one, it indicates a normal adsorption. On the other hand, $1 / \mathrm{n}$ being above one indicates cooperative adsorption, where the function has an asymptotic maximum as the concentration is increased $[13,14]$. These values are shown in Table 2. For nCS1 and $\mathrm{nCS} 3, \mathrm{~K}_{\mathrm{F}}$ were found 5.132 and 0.983 , and $1 / \mathrm{n}$ values of 0.222 and 2.971 respectively. The BGnCS1 and BGnCS3 systems with different grafting percentages showed high values of both parameters with high correlation factors. The values of $\mathrm{n}$ less than one, confirms that Freundlich isotherm is valid for the $\mathrm{Cr}(\mathrm{VI})$ adsorption in the binary grafted copolymer, which was attributed to a heterogeneous surface structure of the new absorbent.

Table 2. Freundlich and Langmuir isotherm parameters for adsorption of $\mathrm{Cr}(\mathrm{VI})$.

\begin{tabular}{|c|c|c|c|c|c|c|}
\hline \multirow{2}{*}{ Adsorbent } & \multicolumn{3}{|c|}{ Freundlich } & \multicolumn{3}{c|}{ Langmuir } \\
\cline { 2 - 7 } & $\mathbf{1 / n}$ & $\mathbf{K}_{\mathbf{F}}$ & $\mathbf{r}^{\mathbf{2}}$ & $\mathbf{Q}_{\mathbf{m a x}} \mathbf{( \mathbf { m g ~ g } ^ { - 1 } )}$ & $\mathbf{K}_{\mathbf{L}}$ & $\mathbf{r}^{\mathbf{2}}$ \\
\hline nCS1 & 0.222 & 5.132 & 0.997 & 24.63 & 0.528 & 0.988 \\
\hline nCS3 & 2.971 & 0.983 & 0.942 & 55.24 & 1.191 & 0.999 \\
\hline BGnCS1 (184\% graft) & 0.841 & 37.367 & 0.981 & 77.52 & 6.45 & 0.996 \\
\hline BGnCS3 (5\% graft) & 3.683 & 6.838 & 0.929 & 2.42 & 0.986 & 0.994 \\
\hline BGnCS3 (21\% graft) & 3.621 & 1.294 & 0.998 & 142.86 & 0.356 & 0.998 \\
\hline
\end{tabular}

The $\mathrm{Cr}(\mathrm{VI})$ adsorption on the binary graft copolymers was also tested with Langmuir isotherm (equation 4). This equation is based on monolayer adsorption onto a surface with finite number of identical sites, homogeneously distributed onto the sorbent surface [15].

$$
\frac{1}{Q_{e}}=\frac{1}{\left(Q_{\max } K_{L} C_{e}\right)}+\frac{1}{Q_{\max }}
$$

where, Qe is the amount of $\mathrm{Cr}(\mathrm{VI})$ adsorbed per unit of copolymer system at equilibrium concentration (mg $\mathrm{g}^{-1}$ ) at different initial solution concentration of $\mathrm{Cr}(\mathrm{VI})$, Ce is the concentration of chromates solution at equilibrium $\left(\mathrm{mg} \mathrm{L}^{-1}\right)$ with different initial concentration solutions of chromates. $\mathrm{Q}_{\max }$ is the maximum capacity of adsorption, corresponding to the total number of interstitial sites in the absorbent and $\mathrm{K}_{\mathrm{L}}$ is the constant of the Langmuir isotherm. The value of the $\mathrm{K}_{\mathrm{L}}$ is related to the affinity of the ions to the adsorption sites, the high values imply a greater affinity of the ions studied towards to the adsorbent. Large $\mathrm{K}_{\mathrm{L}}$ values suggest the stability of sorption complex, which may be the cause of existence of chemical binding forces between chromate anions and surface of the adsorbent. Maximum adsorption capacity obtained for nCS1 and nCS3 was 24.63 and 55.24 $\mathrm{mg} \mathrm{g}^{-1}$, respectively. By other side, the retention behavior in binary grafted systems was dependent of grafting percentages; the optimum retention was obtained from BGnCS3 (21\% graft) with $\mathrm{Q}_{\max } 142.86 \mathrm{mg}$ g-1, higher 
than those values obtained by different researchers $[4,16,17]$. When the percentage was higher, the $\operatorname{Cr}(\mathrm{VI})$ retention decreased because of grafted chains hinder the accessibility to the internal sites or block a number of adsorption sites.

The experimental data fits both Freundlich and Langmuir models for all samples since higher correlation coefficients $(>0.98)$, but Langmuir isotherms exhibited a better coefficients. This means that the adsorption process can be described as a monolayer coverage of the $\mathrm{Cr}(\mathrm{VI})$ onto a surface with finite number of sites, which are homogeneously distributed over the adsorbent. This outcome is similar to the studies involving $\mathrm{Cr}(\mathrm{VI})$ adsorption on chitosan [18].

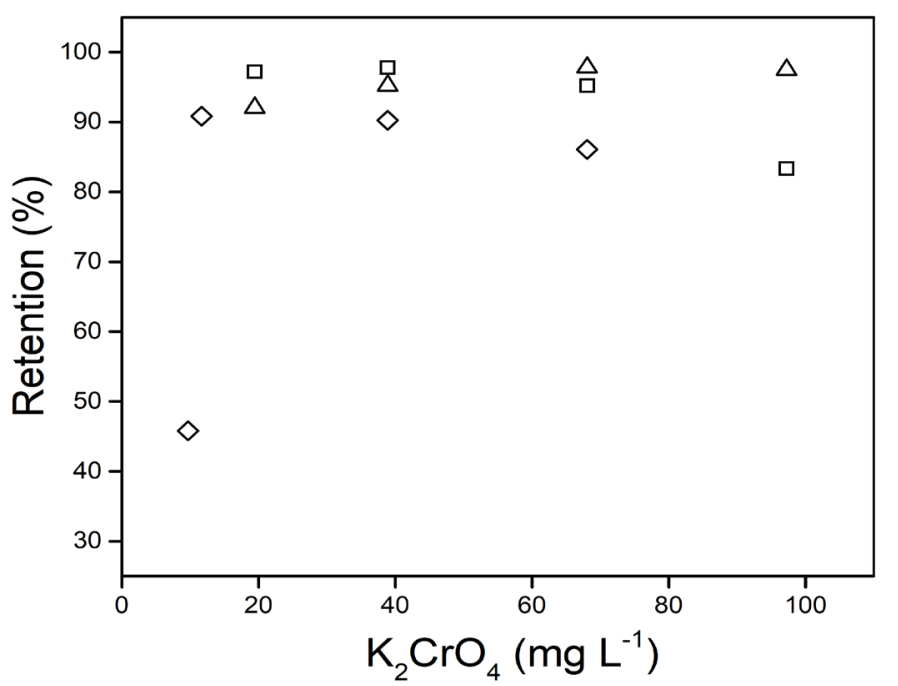

Fig. 4. $\mathrm{Cr}(\mathrm{VI})$ maximum retention percentage as a function of initial concentration of chromate solution, at different grating percentages: $\square$ BGnCS3 (5\%); $\triangle$ BGnCS3 (21\%); $\diamond$ BGnCS1 (184\%).

\section{Characterization Infrared spectroscopy}

To confirm the binary graft copolymerization, the IR spectra of different systems were determined, using a Perkin Elmer 100 Instruments, Norwalk USA, with Universal ATR sampling accessory with 16 scans; they are shown in Fig. 5. The characteristic peaks of nCS appear at $3340 \mathrm{~cm}^{-1}\left(\mathrm{O}-\mathrm{H}\right.$ stretching), $2923 \mathrm{~cm}^{-1}\left(\mathrm{CH}_{2}\right.$ stretching vibration of pyranose ring $), 1652 \mathrm{~cm}^{-1}(\mathrm{C}=\mathrm{O}$ streaching $)$ corresponding to amide of $\mathrm{N}-$ acetylglucosamine units $[16,17]$, and $1568 \mathrm{~cm}^{-1}(\mathrm{C}=\mathrm{N}$ streaching and $\mathrm{N}-\mathrm{H}$ bending $)$ due to imine bonds formed during the crosslinking reaction between CS and formaldehyde [11]. In the BGnCS3 (21\%), only one carbonyl peak was observed at $1638 \mathrm{~cm}^{-1}$ because of the overlap with the carbonyls of DMAAm and NVCL. Once the binary graft system interacted with $\mathrm{Cr}(\mathrm{VI})$, the peak at $1636 \mathrm{~cm}^{-1}$ was wider and a little shoulder appeared at $1579 \mathrm{~cm}^{-1}$, indicating that interaction of material and metal ions was carried out by means amine and carbonyl groups. 


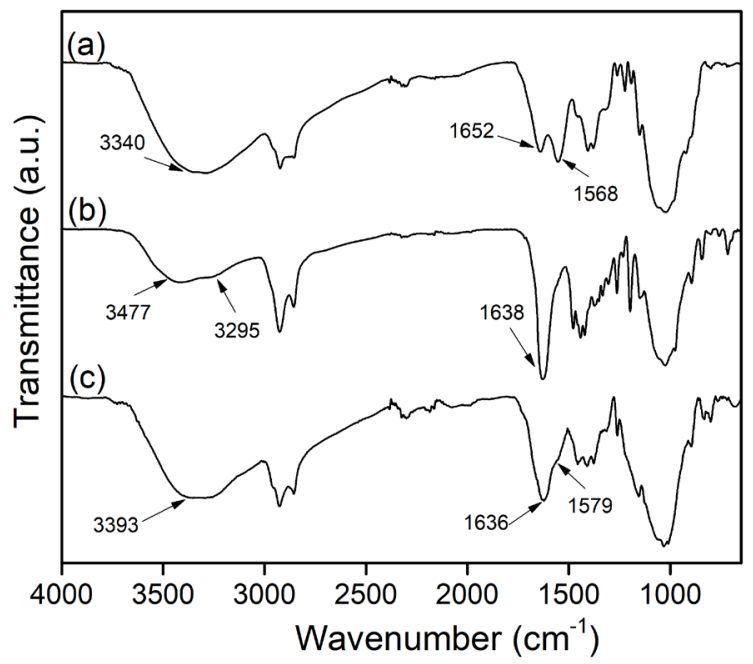

Fig. 5. Infrared spectra of: (a) nCS3, (b) BGnCS3 (21\%), (c) BGnCS3 (21\%) with $\mathrm{Cr}(\mathrm{VI})$.

\section{Thermogravimetric analysis}

The thermal stability of different systems was carried out using a TGA Q50 (TA Instruments, New Castle, DE, USA), in nitrogen atmosphere and a heat velocity of $10^{\circ} \mathrm{C} \mathrm{min}^{-1}$. The thermogram of nCS exhibits a decomposition temperature at $290^{\circ} \mathrm{C}$ corresponding to dehydratation of saccharide rings, decomposition of acetylated units and depolymerization of CS [11]. The binary graft, BGnCS3 (21\%), exhibits two decomposition temperatures, one near $300^{\circ} \mathrm{C}$ corresponding to decomposition of $\mathrm{CS}$, and the other at $410^{\circ} \mathrm{C}$, due to the decomposition of PNVCL and PDMAAm. The $\mathrm{Cr}(\mathrm{VI})$ retention in the system increased the first decomposition temperature and decreased the second decomposition temperature due to interaction of NVCL with chromates ions.

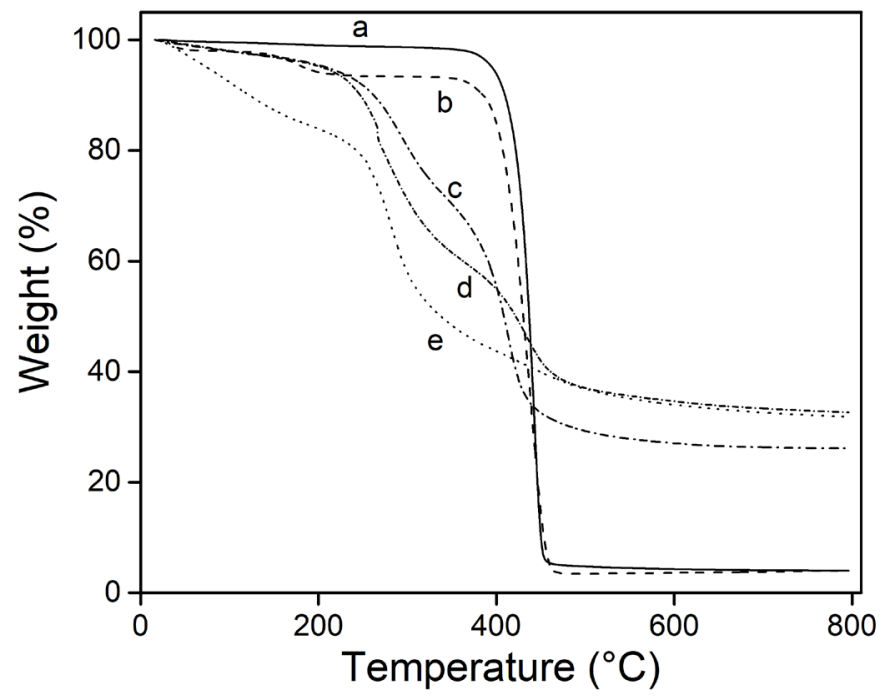

Fig. 6. Thermograms of the different systems: (a) PDMAAm, (b) PNVCL, (c) BGnCS3 (21\%), (d) BGnCS3 (21\%) with $\mathrm{Cr}(\mathrm{VI}),(\mathrm{e}) \mathrm{nCS} 3$. 


\section{Conclusion}

This study aimed for a comparative evaluation of the sorption efficiency of $\mathrm{Cr}$ (VI) onto net-CS, and NVCL/DMAAm grafted onto $n \mathrm{CS}$ using gamma radiation. The characterization showed that $n \mathrm{CS}$ has a lower thermal resistance than binary grafted system. Therefore, $\mathrm{Cr}(\mathrm{VI})$ sorption capacity was higher for BG $n \mathrm{CS} 3$ samples than for $n \mathrm{CS} 3$, showing better apparent mechanical properties. The adsorption data was fitted to both Langmuir and Freundlich isotherms, showing good regression correlation coefficients $\left(\mathrm{R}^{2}>0.98\right)$, but the Langmuir model fitted better. This means that the adsorption process can be described as a monolayer coverage of $\mathrm{Cr}(\mathrm{VI})$ onto material surface with finite number of sites, which predicts that chemical sorption occurred. The maximum retention capacity and removal efficiency were dependent of grafting yield, obtaining the best performance for $\mathrm{BG} n \mathrm{CS} 3$ with $21 \%$ graft. This system showed $\mathrm{Cr}(\mathrm{VI})$ removal efficiencies over $92 \%$ in a wide range of concentrations, and a $\mathrm{Q}_{\max }$ of $142.86 \mathrm{mg} \mathrm{g}^{-1}$. Those values were higher than others founded in the literature, and even better than $n \mathrm{CS} 3$.

\section{Acknowledgements}

The authors wish to thank to M. L. Escamilla, L. M. Valdez, B. Leal and F. Garcia from ICN UNAM, for technical assistance.

\section{References}

1. Wojcik, G.; Neagu, V.; Bunia I. J. Hazard. Mater. 2011, 190, 544-552.

2. Bhattachayra, A. K.; Naiya, T. K.; Mandal, S. N.; Das, S. K. Chem. Eng. J. 2008, 137, 529-541.

3. Singha, B.; Das, S. K. Coll. Surf. B, 2011, 84, 221-232.

4. Burillo, G.; Serrano-Gomez, J.; Bonifacio-Martinez, J. J. Mex. Chem. Soc. 2013, 57 (2), 80-84.

5. Kavakh, C.; Barsbay, M.; Tilki, S.; Guven, O.; Kavakli, P. A. Water Air Soil Pollut. 2016, $227,473$.

6. Wu, F. C.; Tseng, R. L.; Juang, T. S. J. Hazard. Mater. 2001, 81, 167-177.

7. Drobny, J.G. Ionizing Radiation and Polymers: Principles, Technology, and Applications, 2012, 1298.

8. Tinoco, D.; Ortega, A.; Burillo, G. MR Comm. 2018, 8, 617-623.

9. Islas, L.; Burillo, G.; Ortega, A. Macromol. Res. 2018, 690-695.

10. Montes, J. A.; Ortega, A.; Burillo, G. J. Radioanal. Nucl. Chem. 2015, 303, 2143-2150.

11. Perez-Calixto, M.P.; Ortega, A.; Garcia-Uriostegui, L.; Burillo, G. Radiat. Phys. Chem. 2016, 119 , 228-235.

12. Lim, L. Y.; Khor, E.; Koo, O. J. Biomed. Mater. Res. 1998, 43, 282-290.

13. Mohan, S.; Karthikeyan, J. Environ. Pollut. 1997, 97, 183-187.

14. Puttamat, S.; Pavarajarn, V. Int. J. Chem. Eng. Appl. 2016, 7, 239-243.

15. Venckatesh, R.; Amudha, T.; Sivaraj, R.; Chandramohan, M.; Jambulingam, M. Int. J. Eng. Sci. Technol. 2010, 2, 2040-2050.

16. Beppu, M. M.; Vieira, R. S.; Aimoli, C. G.; Santana C. C. J. Membr. Sci. 2007, 301, 126-130.

17. Monier, M. Int. J. Biol. Macromol. 2012, 50, 773-781.

18. Wan Ngah, W. S.; Teong, L. C.; Hanafiah, M. A. K. M. Carbohydr. Polym. 2011, 83, 1446-1456. 